\title{
CONSEQUENCES AND PREDICTORS OF NEW HEALTH EVENTS
}

James P. Smith

Working Paper 10063 
NBER WORKING PAPER SERIES

\title{
CONSEQUENCES AND PREDICTORS OF NEW HEALTH EVENTS
}

\author{
James P. Smith \\ Working Paper 10063 \\ http://www.nber.org/papers/w10063 \\ NATIONAL BUREAU OF ECONOMIC RESEARCH \\ 1050 Massachusetts Avenue \\ Cambridge, MA 02138 \\ October 2003
}

Senior Economist RAND. Paper prepared for Economics of Aging Conference, Carefree, Arizona. I would like to thank the expert programming assistance of David Rumpel and Iva Macclennan. Financial support was provided by the National Institute of Aging. The comments of Dana Goldman, David Cutler, and participants at the Conference are gratefully acknowledged. The views expressed herein are those of the authors and not necessarily those of the National Bureau of Economic Research.

(C2003 by James P. Smith. All rights reserved. Short sections of text, not to exceed two paragraphs, may be quoted without explicit permission provided that full credit, including (C) notice, is given to the source. 
Consequences and Predictors of New Health Events

James P. Smith

NBER Working Paper No. 10063

October 2003

JEL No. I0

\section{ABSTRACT}

Smith uses the HRS and AHEAD panels to examine the consequences of new health on a series of SES related outcomes- out-of-pocket labor supply, labor force activity, household income and wealth. For each of these outcomes, new severe health events have a significant effect although most of the impact on income and wealth takes place through labor supply and not not medical expenses. The paper also examines the ability of different measures of SES to predict the future onset of disease. The author finds no predictive effect of income or wealth but education does predict future onset even after controlling for current health status. The reasons for this continuing predictive effect of education are explored in the paper.

James P. Smith

Senior Economist

RAND Corporation

1700 Main Street

P.O. Box 2138

Santa Monica, CA 90407-2138

smith@rand.org 
There is renewed interest in why people of lower socio-economic status (SES) have worse health outcomes. No matter which measures of SES are used (income, wealth, or education), the evidence that this association is large is abundant (Marmot (1999), Smith (1999)). The relation between SES and health appears also to be pervasive over time and across countries at quite different levels of economic development (Kitagawa and Hauser (1973), Townsend et al. (1988)). Considerable debate remains about why the relation arises and what the principal directions of causation might be ((Smith (1999), Adams et al. (2003), Deaton (2003)). However, many analytical difficulties exist when one tries to understand its meaning. These difficulties include the complex dimensionality of health status that produces considerable heterogeneity in health outcomes, the two-way interaction between health and economic status, and the separation of anticipated from unanticipated health or economic shocks.

The emphasis in health research has been on understanding and disentangling the multiple ways in which socio-economic status may influence a variety of health outcomes. Consequently, much less is currently known about the impact health may have on SES. But at least for working-aged individuals, health feedbacks to labor supply, household income, and wealth may be quantitatively quite important. Therefore, one aim of this paper will be to estimate the effect of new health events on a series of subsequent outcomes that are both directly and indirectly related to SES. These outcomes will include out-of-pocket medical expenses, the intensive and extensive margins of labor supply, health insurance, and household income.

Finding evidence that there are significant feedbacks from new health events to these subsequent correlates of SES does not negate the real possibility that the probability of experiencing the onset of a minor or major new health event may not be uniform across several SES dimensions. This pathway is also explored here by examining whether the onset of new 
chronic conditions is related to household income, wealth, and education once one conditions for a set of pre-existing set of demographic and health conditions.

This research will use multiple waves of data on health status and transitions, medical expenses, labor supply, income, and wealth accumulation from the first five waves of the Health and Retirement Survey (HRS). HRS is a national sample of about 7,600 households $(12,654$ individuals) with at least one person in the household 51-61 years old originally interviewed in the fall of 1992 and winter of 1993. The principal objective of HRS is to monitor economic transitions in work, income, and wealth, as well as changes in many dimensions of health status. The first follow-up of HRS respondents was fielded approximately two years after the baseline. HRS instruments span the spectrum of behaviors of interest: on the economic side, work, income and wealth; on the functional side, health and functional status, disability, and medical expenditures.

The paper is divided into three sections. The first documents the considerable amount on new health activity that afflicts individuals during their fifties and early sixties. The second section analyses the impact of these new health events on a series of outcomes-medical expenses, work effort, income, and health insurance. In the third section, this perspective is reversed by examining which dimensions of SES — income, wealth, and education —are able to predict future health outcomes.

\section{Section 1. The Best of Times and the Worst of Times}

Matters are pretty quiet for most people on the economic front when they are in their fifties. For better or worse, what one does for a living has long since been settled and salary adjustments stick pretty closely to CPI swings. But it is anything but quiet and settled on the health front. Table 1 documents the extent of this activity by listing in the first column 
prevalence rates of major and minor chronic conditions for respondents who were members of the original HRS cohort (those born between 1931 and 1941). Major conditions were defined as cancer, heart condition, stroke, and diseases of the lung. All other onsets are defined as minor. At baseline in 1992, 39\% of HRS respondents claimed to have no chronic conditions at all while $43 \%$ reported that they had had some minor onset sometime in the past. About one in five stated that they already had experienced a major condition onset. ${ }^{1}$

The extent of the new health problems reported during these eight years is impressive if not depressing. Independent of their baseline status, about half of all respondents experienced some type of onset during the first five HRS waves. Note that the conditional probability of a major onset is much higher if one had already reported some type of health problem at HRS baseline than if one was chronic condition free. To illustrate, the probability of experiencing a major onset sometime after HRS started is $53 \%$ higher if one had a minor condition at baseline instead of having no chronic condition at all. This no doubt reflects the progressive nature of disease whereby having relatively minor medical problem (such as hypertension) heightens the odds of experiencing another much more severe one (such as a heart attack).

The final column in Table 1 looks back and summarizes the consequences of all this activity by listing prevalence rates at the end of the $5^{\text {th }}$ round of HRS. By this time, more than four out of every five HRS respondents had experienced an onset of some chronic condition, and for a third of them the onset was one that I label major. In less than a decade, the fraction of respondents without any health condition was cut in half while the proportion with a severe health problem doubled.

\footnotetext{
${ }^{1}$ In this and all other tables in this paper, major trumps minor. That is, an individual who reports both a minor and major onset is included in the major category.
} 
While certainly a real concern for the families involved, the sheer extent of this new and largely negative health activity raises several analytical questions and opportunities for research. The most direct question involves what the financial consequences of this health deterioration might be, an issue I address in the next section. The analytical opportunities stem from the considerable variation in individual health status during these ages, especially compared to that observed in the standard mainstays of life-cycle models.

\section{Section 2. The Consequences of New Health Events}

It is useful to first outline the essential issues in estimating effects of SES on health as well as the effects of health on SES. Current realizations of both economic status and health reflect a dynamic history in which both health $\left(\mathrm{H}_{\mathrm{t}}\right.$ and SES $\left(\mathrm{Y}_{\mathrm{t}}\right)$ are mutually affected by each other as well as by other relevant forces. Most of the relevant ideas can be summarized by the following two equations:

(1) $\mathrm{H}_{\mathrm{t}}=\alpha_{0}+\alpha_{1} \mathrm{H}_{\mathrm{t}-1}+\alpha_{2} \mathrm{Y}_{\mathrm{t}-1}+\alpha_{3} \Delta \mathrm{Y}_{\mathrm{t}}+\alpha_{4} \mathrm{X}_{\mathrm{t}-1}+\mathrm{u}_{1 \mathrm{t}}$

(2) $\mathrm{Y}_{\mathrm{t}}=\beta_{0}+\beta_{1} \mathrm{H}_{\mathrm{t}-1}+\beta_{2} \mathrm{Y}_{\mathrm{t}-1}+\beta_{3} \Delta \mathrm{Ht}+\beta_{4} \mathrm{X}_{\mathrm{t}-1}+\mathrm{u}_{2 \mathrm{t}}$

where $\mathrm{X}_{\mathrm{t}-1}$ represents a vector of other possibly non-overlapping time and non-time varying factors influencing health and SES and $\mathrm{u}_{1 \mathrm{t}}$ and $\mathrm{u}_{2 \mathrm{t}}$ are possibly correlated stochastic shocks to health and SES. The key parameters $\alpha_{3}$ and $\beta_{3}$ measure the effects of new innovations of SES on health, and health on SES respectively. In this framework, we can also estimate whether past values of SES predict health $\left(\alpha_{2} \neq 0\right)$ or past values of health predict SES $\left(\beta_{3} \neq 0\right){ }^{2}$

To estimate the "effect" of either on the other $\left(\alpha_{3}\right.$ and $\left.\beta_{3}\right)$, we require exogenous variation in health (or SES) that is not induced by SES (health). In an earlier paper (Smith 1999), I

\footnotetext{
${ }^{2}$ For an insightful debate about the conditions under whether coefficients are zero or stationary also reveals something about causality, see the paper by Adams et al. (2003) and the comments on that paper in the same volume.
} 
proposed one research strategy for isolating new health events - the onset of new chronic conditions. While to some extent people may anticipate onset, much of the actual realization and especially its timing may be unanticipated. While new onsets may provide the best chance of isolating health shocks, not all new onset is a surprise. A set of behavioral risk factors and prior health or economic conditions may make some people more susceptible than others to this risk. Thus, predictors of new onsets should be included in models to increase one's confidence that the remaining statistical variation in new onsets is "news." Similarly, to estimate $\alpha_{3}$ we require variation in SES not induced by health and my approach to this issue will be outlined in the next section. In this section, I present my results for equation 2 above- the effect of health on SESand in the section that follows I discuss my results relevant to equation 1.

One thing that may happen when people become newly sick is that their medical expenses may rise, and the extent to which they rise may be influenced by the continued presence of health insurance. But medical expenses are by no means the only way health shocks can affect wealth accumulation. Most directly, healthier people may work longer hours in any given week and more weeks during a year, both of which may lead to higher earnings. To estimate the impact of the onset of new health conditions, a parallel set of models is estimated predicting out-of-pocket medical expenses, the continued possession of health insurance, labor supply, household income, and wealth or savings.

A new health event in one year may affect medical expenditure, labor supply and income not only in the year in which the event occurred but in future years as well. For example, at one extreme, the onset of a new condition may induce only single period changes in labor supply after which labor supply may stabilize. But it is possible that spillover effects of a health shock may further depress work effort in future years or alternatively some recovery to original levels 
may take place. One way of estimating such patterns is to estimate a series of four equations for each of HRS waves 2-5 summarizing changes in each outcome between adjacent waves, say

$$
\Delta \boldsymbol{L}_{t}=\alpha \boldsymbol{X}+\sum_{t=2}^{5} \beta_{t} \Delta \boldsymbol{H}_{t}
$$

where $L_{t}$ is the between-wave change in labor supply and $H_{t}$ the within-period health event from period t to t-1. Similar equations would apply for household income, out-of-pocket medical expenses, and other outcomes. If there are only contemporaneous one period effects of health events, all lagged values of $\mathrm{H}_{\mathrm{t}}$ will be zero. ${ }^{3}$

X represents a vector of baseline HRS attributes that include baseline measures of birth cohort (or age), marital status, race, ethnicity, education, region of residence, quintiles of family income, and a vector of measures of baseline health. These health measures include dummies for four of the five categories of self-reported health status, the presence of each chronic condition, a set of behavioral risk factors (smoking, exercise, BMI, drinking), and a scaled index of functional limitations based on the answers to the ADL questions. Given these extensive set of baseline health controls, the new onset of chronic conditions in each wave captures the impact of a new health event that is not predicted by (observed) baseline health and to that extent may be labeled news.

While this formulation has been simplified into a single type of new health event $\left(\mathrm{H}_{\mathrm{t}-\mathrm{i}}\right)$, different kinds of health changes may have quite different economic consequences (Smith 1999). Health events can be distinguished by their severity, immediacy, impact on functioning, and duration. For example, the onset of hypertension may have no immediate consequences, but it

\footnotetext{
${ }^{3}$ All models in this paper are restricted to survivors - those who neither attrited nor died across the waves - so this analysis ignores the relationship of SES with attrition and mortality. Given the age range of HRS respondents, mortality selection but not attrition is unlikely to be that critical. That is clearly not the case in the AHEAD sample. For a model that incorporates mortality selection see Adams et al. (2003).
} 
may signal a more difficult future. In contrast, a heart attack or stroke has devastating immediate and future effects on medical expenditures and work effort. At this point in the research effort, I have made only one simple distinction — whether the health event is classified as severe or minor. Further distinctions will be pursued in the future and will largely be an issue of how much data are required.

\section{Medical Expenses and Health Insurance}

One quite direct financial impact of a health onset may be the additional medical costs that are incurred. While some combination of private and public health insurance will pay the bulk of these costs, insurance does not cover all of them. Some people may lack health insurance, and even for those who have it not all medical costs are covered either due to caps or exclusion of certain benefits such as drugs. Table 2 presents the distribution of total out-ofpocket medical expenses associated with an onset of a new health condition that took place between the baseline and second wave of HRS. That onset could have been either a major or minor one and separate OOP expense distributions are presented for each situation. These medical costs are measured over the first five waves of HRS and thus are cumulative across eight years. The reference group in Table 2 is those HRS respondents who had no medical onset at all across the first five survey waves.

The incremental mean medical expenses associated with a severe health onset are about $\$ 5,500$ and only about $\$ 1,600$ if the onset was one I label mild. Given that the time period spans eight years, these are modest sums. However, not all appears modest and there may be considerable financial risks associated with new medical problems. For example, after experiencing a severe onset there is a $10 \%$ chance that OOP medical expenses over the next year will increase by $\$ 17,000$, a one-in-twenty chance that they will increase by about $\$ 25,000$, and a 
one-in-fifty shot of an increment of more than $\$ 40,000$. However, these financial risks of additional medical expenses are mostly associated with severe onsets. If the onset was one within the mild category, the mean impact of $\$ 1,600$ is a reasonably good descriptor of shift in the entire OOP cost distribution. For example, compared to a mean estimate of $\$ 1,600$, there is a one-in-twenty chance of a $\$ 2,800$ increase in OOP medical expenses when the new onset was mild.

The cost data contained in Table 2 describe the cumulative impact of a new onset. To describe year-by-year flows, Table 3 presents estimates of the mean increase in OOP expenses due to the period-by-period onset of new medical conditions. As described above, these estimates are based on models that control for pre-existing health conditions, economic status, and a standard set of demographics. Four sets of models are estimated —one each for the amount of OOP medical expenses that took place between successive waves. Each model includes as covariates all prior wave health shocks. The rows in Table 3 represent the wave at which HRS OOP medical costs are measured, and the columns the time of onset of new health condition. The final row sums these period costs to compute the cumulative (up to wave 5) increase in OOP medical costs associated with each medical event.

Thus, a severe health shock that occurred between waves 1 and 2 of HRS initially increased mean OOP medical expenses by $\$ 1,720$ during the two-year interval when it happened. This same health event also produced future increases in health costs that were of progressively smaller amounts. By the fifth wave, the mean total cost was a little over $\$ 4,000$ so that less than half of the incremental costs were borne around the time of the event. Roughly speaking, the same pattern exists for major health events taking place in other HRS waves - an initial mean impact of about $\$ 2,000$ followed by additional albeit falling cost increments in future years. 
These estimated increases in total OOP medical costs in Table 3 are not all that different than the simple unadjusted differences displayed in Table 2 suggesting that these additional costs are due to the actual onset and not the result of other (measurable) differences at baseline between those who actually experienced a major health event and those who did not.

The primary purpose of health insurance is to reduce this financial risk. The second and third panels of Table 2 present the same type of data on the distribution of OOP medical expenses, but this time stratified by whether or not the respondent had health insurance at baseline. Health insurance certainly dampens but does not eliminate medical costs due to new major illness. The mean increase in OOP medical costs is around $\$ 5,000$ among those with health insurance and about twice that amount for those without health insurance. A comparison of the impact of a severe health event by insurance coverage shows that expenditures are actually lower at and below the median respondent without health insurance, but that they become progressively greater for the uninsured in the right tail of the cost distribution. This suggests that there is an impact of insurance on utilization as well as on expenditures. The lower impact of a severe onset below the median for those without health insurance may indicate that those without insurance went without some care costing moderate amounts. But some of the large expenses appear to have been borne by those without health insurance.

The financial risks of health events remain for all HRS respondents. Even for those with health insurance at baseline, there is a one-in-twenty chance of an increase in expenses of about $\$ 11,000$ and a one-in-fifty of about $\$ 23,000$ additional outlays. Of course, the situation is far more difficult among those without baseline health insurance where even the mean effect of a new severe onset is about $\$ 10,000$. For them, there is a $10 \%$ chance of $\$ 28,000$ more in OOP medical costs, and a 5\% chance of an extra $\$ 73,000$ in additional expenses. In contrast, the shift 
in expense distribution induced by a minor onset is not large whether or not the respondent was covered by health insurance.

The data in Table 2 control for the presence of health insurance at baseline. One fear associated with becoming sick is the possibility of losing health insurance, especially if one can no longer work. For those without health insurance, the concern is that it may now be almost impossible to obtain it. Table 4 addresses this issue by listing the fraction of HRS respondents who reported no type of health insurance in each wave. As they age into government programs like Medicare, even among those who experienced no new health events across the first five waves the percent without health insurance fell in half (from 14\% to 7\%). Table 4 also lists the same data for respondents who experienced a new major health event between each wave. The timing of the new health event is indicated by the placement of the dotted lines in each column. While each of the last four columns shows the same downward trend in non-coverage, in each case there is a noticeable jump at the time the major health event occurred. ${ }^{4}$

Table 5 provides a more detailed look at what is happening by listing the types of health insurance held at each wave. At baseline, among those HRS respondent with health insurance the dominant mode by far is employer-provided insurance, but as the waves unfold and retirement comes closer there is a gradual transition toward more government provided insurance. But with what looks like a one period lag, this transition is clearly accelerated by a new major event. For example, between the second and fourth waves of data, there is a 25 percentage point drop in employer-only coverage and a 20 percentage point increase in government-only coverage. This compares to only a 10 percentage point drop in employer and 12 percentage point increase in government coverage for those experiencing no new health events. The data in Appendix Table A demonstrates that virtually all of this expansion in

\footnotetext{
${ }^{4}$ There were no such breaks for new minor health events.
} 
government-provided health insurance was Medicare and not either Medicaid or Champus - the two other major government programs.

Instead of new major health events raising the prospects of a loss of health insurance they actually triggered new (earlier) eligibility and lead to an expansion in insurance. This indicates that in terms of the consequences of health events the pre-retirement years represented by the original HRS cohort might be quite unique and should not be extrapolated to younger people.

\section{Work and Income}

New health events can impact the financial well being of households in other ways as well. Perhaps, the most direct is that declining health may make work more difficult. Following the same format used in Table 3, Tables 6, 7, and 8 summarize the estimated effects of new health shocks on changes in the probability of work, changes in the number of hours worked per week (conditional on working), and changes in household income.

Similar to the time pattern of effects documented earlier for OOP medical expenses, a new severe health onset has an immediate and large impact of reducing the probability of working, which is then followed by diminishing ripple like effects in subsequent waves. To illustrate, a severe health event between the first and second wave of HRS reduced the probability of work by 15 percentage points between the same two waves. Since the average labor force participation rate at baseline among those who were about to experience this major health event was .55 , the impact on work is decidedly not trivial. Once again, estimated incremental effects in subsequent years cascade downward so that by the end of HRS wave 5, the probability of work had declined by about 27 percentage points due to a major health shock between waves 1 and 2. This pattern of a large immediate reduction in the probability of work followed by smaller additional declines in future waves also characterizes major health events 
that took place between the other waves of HRS. There appears to be a small decline in the absolute size of the impact on work effort, which would not be surprising as labor force participation is trending down as HRS respondents age. Just as was reported for medical costs, estimated effects are considerably smaller if the health events come under the minor label.

In contrast to these quite dramatic impacts on the probability of work, the estimated effects on my measure of the intensive work margin-weekly hours conditional on work shown in Table 7-are not only more modest in their immediate impact, but the contemporaneous effects are about the same as the cumulative effects indicating little spillover to future years. Apparently the principal way that work is altered by a new severe health event is through the extensive margin of whether one works or not.

Table 8 provides estimates of the biannual changes in annual household income that are associated with new health events. While labor force activity refers to the same time as the survey, it is important to remember that household income is for the previous year so that some part of total income receipts actually predates the onset of the disease. In addition to betweenwave household income changes presented in the first four rows of this table, the final two rows provide two summary measures of cumulative change over the first five waves. The first - total yearly income loss — was obtained from summing the column estimates and thus measures the difference in household income between wave 5 and the wave preceding the new health event. The second - cumulative income loss - measures the total loss in household income associated with the health event.

Not surprisingly given the labor force results described above, new health events reduce household income with the reduction larger when the shock is major. There is no evidence of any household income recovery in subsequent years so that the initial income losses persist. In 
fact, consistent with the labor force participation effects, there are additional diminishing income losses in subsequent waves. These period-by-period income losses while cumulatively significant are much smaller than the reductions in work force participation contained in Table 6. Off their baseline levels, household income declines are in the order of $10 \%$ or less compared to close to $30 \%$ for workforce participation. The reasons for this discrepancy in the two related outcomes do not lie so much in offsets in other types of income (for example I find little evidence of additional work effort of spouses) but instead in different reactions to similar health shocks across the income distribution. Low-income households are much more likely to react to a health shock by exiting the labor force than are higher-income households.

The final row in Table 8 presents the cumulative household incomes loss associated with the health event. ${ }^{5}$ Evaluated using mean effects, cumulative household income losses are much larger than the cumulative increases in OOP medical expenses described above in Table 3. For example, for the wave 1-2 major health shock, the order of magnitude is ten to one. While less dramatic for the severe health shocks in the other waves, cumulative income losses typically exceed cumulative medical expenses by a large single-digit integer.

Table 9 contains my estimates of the sum of cumulative income loss plus cumulative medical expenses associated with the onset of a health event derived from these models. The lifetime budget constraint linking consumption, income, assets, and savings implies that this sum of income loss plus cumulative medical expenses (plus the foregone interest on them) represents an alternative way of measuring the wealth change or savings that took place across the first five waves of HRS.

\footnotetext{
${ }^{5}$ I assume that the health event took place midway between the waves so the income loss coincident with the health event applies initially for only one year.
} 
There are several advantages and disadvantages with this alternative measure of the household savings. Since income is arguably measured with much greater accuracy than household wealth, this alternative concept should be less contaminated by measurement error than changes in household wealth are known to be. Second, this alternative measure is also less affected by capital gains, which during the periods of the recent stock market boom and bust may well dominate changes in household wealth over time. The principal disadvantage is that this alternative measure does not incorporate changes in other components of household consumption besides medical expenses. Invoking standard consumption smoothing arguments may not be a sufficient safe harbor as standard inter-temporal theory suggests that consumption adjustments may be triggered in part by new health events.

With these caveats, the data in Table 9 indicate that the onset of all major health events should have lead to a reduction in household wealth with that reduction much larger for major health events compared to the more minor ones. Table 9 also includes the same summary measures of household income loss and cumulative medical expenses that were obtained from precisely the same models estimated using the original AHEAD sample. Given the predominance of retirement and virtually universal coverage by Medicare in the AHEAD sample, not surprisingly the implied change in household wealth triggered by a new health event whether it is major or minor is considerably smaller in the AHEAD sample. In the AHEAD sample, there is much less possibility of any income loss since most respondents' income is either annutized or is not contingent contemporaneously on changes in health status (see Smith and Kington (1997) for additional evidence).

Table 10 lists results of models that use two alternative measures of changes in household wealth - the cumulative income loss and OOP medical expenses plus the implicit foregone 
interest on them (labeled the cumulative model) and the more direct measure using the change in household wealth between the first and fifth wave of HRS - as the outcome variables. In this formulation, negative coefficients in cumulative model imply positive household wealth growth so that the coefficients in the two alternative models should have opposite signs. In most cases, this turns out to be the case and estimated coefficients are often remarkably close especially as there is nothing at the measurement level tying these two outcomes together.

The principal difference between the two models lies in fact in the final row-the $\mathrm{R}^{2}$ that are more than eight times larger in the cumulative model. The negative consequences of the considerably greater measurement error in household wealth are apparent from the much larger standard errors, lower statistical significance, and somewhat wilder fluctuation in estimated coefficients (when one would think they might be ordered as in baseline self-reported GHS) in the household wealth model compared to the cumulative model.

At least if only signs are used as the criteria, there are many similarities in the estimates obtained with the two alternative outcome measures. Since these similarities are not forced through measurement, this may encourage at least some of us to assign more credibility to some of the results. For example, both outcome specifications predict that younger HRS respondents experienced greater wealth growth over these eight years and that wealth growth was somewhat smaller among women, African-Americans, and Latinos. Finally, additional years of schooling — and most particularly having a college degree—are associated with larger amounts of wealth accumulation under either definition of the outcome.

The major exception to this theme of overall similarity concerns the household income and wealth variables, which have the same signs in both models in the first and third columns of Table 10. Since additional financial resources should promote savings, the a priori expectation 
is that the baseline financial variables should be negative in the cumulative model and positive in the wealth change specification. But this is only the case for wealth in the model where income is included in the outcome (the cumulative model) and household income in the wealth change model. The reason for this confusion stems from the impact of measurement error in both income and wealth, which when appearing on both sides of the estimated equation seriously biases the estimated coefficients. The second and fourth columns omit the guilty party from the respective models, and much more sensible estimates are now obtained for the effect of wealth in the cumulative model and the effect of income in the wealth change model. Both estimates now imply reasonable ranges of the marginal propensity to save. By and large the estimated effects of other variables in the model are not sensitive to these alternative specifications.

My principal interest in these models concerns the impact of a new health event. I concentrate only on the impact of new health events between waves 1 and 2 . In the cumulative model, the estimates of household savings induced by the major and minor health onset are close to those obtained by summing the individual wave estimates that were summarized in Table $9-\mathrm{a}$ major health onset lead to a cumulative loss of about $\$ 52,000$ and a minor one a cumulative loss of about $\$ 11,000$. Both minor and major health onsets also lead to a cumulative wealth lost when wealth change models are examined. However, estimates now are not terribly precise-a predictable consequence of poorly-measured household wealth in the HRS panel.

I also examined whether or not there were important interaction effects of a new health onset by interacting the two health event onset variables with race, gender, ethnicity, education, income, and wealth. None of these interactions were significant except wealth in the cumulative model and baseline household income in the wealth change model. In both cases, the effects of a major health onset were larger the higher baseline wealth or income. For example, the impact of 
a major health event in reducing wealth growth was larger the higher initial levels of household income. This finding is consistent with a combination of consumption smoothing and liquidity constraints. Lower-income households are forced to absorb more of the wealth change in consumption.

\section{Section 3. Predictors of New Health Events}

In this section, I reverse the question by examining the ability of baseline SES measures to predict the future onset of disease once one controls for measures of baseline health. I also explore the extent to which innovations in economic status 'cause' changes in health.

Table 11 contains the results obtained from probit models predicting the onset of a major or a minor chronic condition between waves 1 and waves 5 of HRS. These models include as covariates a vector of baseline health conditions of the respondent-self-reported general health status (excellent, very good, good, with fair and poor the excluded class), the presence of a chronic condition at baseline, a scale measuring the extent of functional limitations (from 0 to 100 with higher numbers indicating poorer functioning). The models also include a standard set of behavioral risk factors (currently a smoker, number of cigarettes smoked), whether one engaged in vigorous exercise, and BMI (entered as quadratic), and a relatively standard set of demographic controls - birth cohort (born between 1935-1937, after 1937 with pre 1935 or the

older respondents the excluded group), race (1= African-American), Hispanic ethnicity, and sex (1= women), and region of residence. My main interest lies in the SES measures that include household income, household wealth, and respondent's education (two dummies-12-15 years of schooling, 16 or more years, with less than 12 the excluded group).

Just as one needed innovations in health that were not caused by SES to estimate the impact of health on SES, it is also necessary to isolate innovations in SES that were not caused 
by health to estimate the impact of SES on health. One opportunity for doing so lies in the large wealth increases that were accumulated during the large stock market run-up during the 1990s. Given the unusually large run-up in the stock market during these decades, it is reasonable to posit that a good deal of this surge was unanticipated and thus captures unanticipated exogenous wealth increases that were not caused by a person's health. If financial measures of SES do improve health, such increases in stock market wealth should be associated with better subsequent health outcomes at least with a lag. ${ }^{6}$

Putting aside for a moment the central SES results, most of the estimates listed in Table 11 are as expected. Older respondents are much more likely to experience a new chronic onset, and the likelihood of experiencing a new onset is strongly negatively related to better health status as measured at baseline. There are some suggestions of some to-do's and not-todo's from the health behavioral risk variables. Even after controlling for an extensive list of baseline health conditions, smoking, excessive drinking, and the absence of vigorous exercise places one at elevated risk for the onset of a new major condition but appears to have little impact on the minor onsets. Women, Latinos and perhaps somewhat surprisingly AfricanAmericans are all of lower risk of a major new onset while only African-Americans face a statistically significant higher risk of a new minor onset.

My principal interest in these models is whether prior wave SES predicts the likelihood of new illnesses, and if so which measures of SES, and if so why? A pretty consistent generalization can be made for household income - it never predicts future onset on minor or major conditions. While household wealth appears to be only related to a major onset, this effect is not particularly large and as we shall see below it will mostly disappear with a single

\footnotetext{
${ }^{6}$ One limitation of using increases is stock market wealth is that these increases are concentrated at the top of the income distribution (see Smith (2000)). Obtaining other credible measures of exogenous changes in financial resources that more evenly span the entire income distribution would be very useful.
} 
exception when I break out the different types of chronic onset. Finally, my best measure of an exogenous wealth change - the wealth increase from the stock market — is only statistically significant in one instance (arthritis) and there it has the incorrect sign so that an increase in stock market wealth makes the onset of arthritis more likely. Moreover, in results I do not display in Table 11, having health insurance also does not predict future onset. In sum then, SES variables that directly measure or proxy for financial resources of a family are either not related or at best only weakly related to the future onset of disease over the time span of eight years.

This largely negative conclusion is in sharp contrast to the results obtained for the final SES measure - education and for the gist of the results reported by Adams et al. (2003) for a mostly retired population. Additional schooling is strongly and statistically significantly predictive of the new onset of both major as well as minor disease over the first eight waves of the HRS.

To obtain some notion of why all this may be so, Table 12 lists estimated coefficients for the SES variables obtained with models for each of the chronic conditions separately. In no single case is the estimated coefficient on household income (which vacillates in sign) statistically significant. While the coefficients on wealth lean towards negative values, in only one case (stroke) is a statistically significant result negative result obtained for household wealth. Combined these results in Table 12 strengthen the overall conclusion that in a sample of the preretirees financial measures of SES do not appear to be able to predict future onset of disease across a time horizon of almost a decade.

Once again, however, in all cases except cancer (which looks very much like an equal opportunity disease), the effects of schooling are preventative against disease onset. But here too 
disease differentiate may eventually be informative as the most powerful protection of education takes place for arthritis and diseases of the lung with diabetes and heart disease in the next tier.

That leaves us with the most difficult question of all—why does education matter so much? To try to provide at least some partial insight into this question, I ran an expanded version of these models. This expansion involved including some of the more likely prospects that are measured in the HRS — cognition, past health behaviors, early life health and economic environments, parental attributes and parental health. HRS information on some of these concepts is quite limited but it does record whether one smoked in the past and whether one was exposed on the job to a health hazard (and the number of years of exposure), the education of parents, whether or not each parent is alive, and if deceased the age of death, self-accessed general health status as a child (the same five point scale), and an assessment of the economic environment in which one lived during childhood. ${ }^{7}$ The results obtained from this expanded model are presented in Table 13 (for major onsets) and Table 14 (for minor offsets).

First, lets deal with the easier question - which of these new measures did not seem to matter in this context. Two of the more prominent cognition variables available in the HRS were added to these models - memory word count and the Wechsher scale (a measure of higher order reasoning). Neither of these cognition variables was statistically significant and their inclusion had no impact at all on the education variables. The same conclusion would apply to the exsmoker variable, the environmental job exposure variable, and parental education. ${ }^{8}$

\footnotetext{
${ }^{7}$ The specific question for health was "Consider your health while you were growing up, from birth to age 16 . Would you say that your health during that time was excellent, very good, good, fair, or poor?" The specific question for economic circumstances was "Now think about your family when you were growing up, from birth to age 16. Would you say your family during that time was pretty well off financially, about average, or poor?" ${ }^{8}$ When individual chronic conditions were examined separately, the environmental exposure variable has a statistically positive effect on diseases of the lung.
} 
What did matter was the self-evaluation of childhood health and economic status and parental health as proxied by age of death of each parent. ${ }^{9}$ For the major health onsets, a (currently) self-assessed better health status and better economic status during childhood both reduce the risk of incurring a serious health onset in one's fifties and early sixties even after controlling for current health and economic status. There is, of course, ample support for such a finding in the work of Barker (1997) and others who have emphasized the delayed health impact of early childhood exposures. I would currently view these results more cautiously until the disease specific relevance can be rationalized. For example, when models are estimated on the individual diseases separately, the principal impacts of childhood health appear in heart disease and diseases of the lung (and not cancer). More puzzling, the major impact of childhood economic circumstances appears in cancer for which a convincing explanation does not immediately jump to mind.

In the minor onset specification in Table 14, what principally matters are the measures of parental health. Having a living parent or having a parent being older when they died tend to reduce the likelihood of an onset on new chronic conditions. When these are estimated on a disease specific basis, the effects are concentrated in hypertension and diabetes and pretty much non-existent in arthritis. The same caveats mentioned above for the major onsets would apply here as well.

With these additional variables included, the effects of own education in predicting onsets appears to be diminished but the principal impact may have been more on standard errors

\footnotetext{
${ }^{9}$ For evidence of the role of economic resources during childhood, see Case, Lubotsky, and Paxson (2002) and Wadsworth and Kuh (1997).
} 
than on point estimates. My admittedly tentative conclusion would be that collectively these additional factors explain some but not all of the ability of education to predict future onset. ${ }^{10}$

\section{Conclusions}

In this paper, I examined several questions related to the SES health gradient using a sample of people first observed when they were mostly between ages 51 and 61 . This research was based on extensive data about baseline health and several dimensions of their SES as well and the update on this information available from four subsequent follow-ups taking place at two-year intervals. Innovations in health are proxied by the new onset of chronic conditions, a relatively common event in this age group, and innovations in economic status by the change in stock market wealth over this period.

There are some things that appear clear. Among people in their pre-retirement years, feedbacks from health to labor supply, household income, and wealth are realities that should neither be ignored nor dismissed as of secondary importance. Working is the critical link in this chain with OOP medical expenses, while not ignorable especially for distributional analysis, in the second tier. These negative income and wealth consequences of new health innovations do appear to decay with age and are certainly much smaller in an already retired population. What these consequences would be 10 or 20 years earlier in age is an important and yet unanswered question (see Smith (2003). The evidence is this paper along with that available in other studies (Adams et al. (2003), Smith (1999)) means that we can say with more confidence that health has quantitatively strong consequences for several dimensions of SES, particularly financial ones in certain age groups.

\footnotetext{
${ }^{10}$ For an alternative explanation of the role of disease self-management in the health education gradient, see Goldman and Smith (2002).
} 
More tentative conclusions are warranted for the ability of SES measures to predict future onset of disease. Perhaps, most importantly, my evidence does suggest that the role of financial measures of SES — household income, household wealth, or health insurance—is quite weak. To put it most simply, household income never appears to predict any future onset over the horizon of about a decade and there is only weak evidence that levels of changes in household wealth helps much at all. However, it is not true that SES doesn't matter. Even after controlling for an extensive list of baseline health conditions and status, education still strongly predicts the future onset of disease.

My attempts to explain why education may matter represent the most tentative part of my thinking. There is evidence that the pathways may well be disease specific as the predictive power of schooling varies considerably by disease. There is also some evidence that legacy effects from childhood may still matter 30 or 40 years later even when the health outcome is the onset of new disease. Whether or not these legacy effects represent economic, health, or genetic factors is quite uncertain in my view and requires much more additional research. 


\section{References}

Adams, Peter, Michael Hurd, Daniel McFadden, Angela Merrill, and Tiago Ribeiro. "Healthy, Wealthy, and Wise? Tests for Direct Causal Paths Between Health and Socioeconomic Status," Journal of Econometrics 112:3-56, 2003.

Barker, David J. P. "Maternal Nutrition, Fetal Nutrition and Diseases in Later Life," Nutrition 13(9):807-13, 1997.

Case, Anne, Darren Lubotsky, and Chris Paxson. "Economic Status and Health in Childhood: The Origins of the Gradient, "American Economic Review 92(5):1308-34, December 2002.

Deaton, Angus. "Health, Inequality, and Economic Development," Journal of Economic Literature, 41:113-58, March 2003.

Goldman, Dana, and James P. Smith. "Can Patient Self-Management Help Explain the SES Health Gradient?" Proceedings of the National Academy of Sciences; USA (PNAS), 99(16):10929-34, August 6, 2002.

Kitagawa, Evelyn, and Philip Hauser. Differential Mortality in the United States: A Study in Socioeconomic Epidemiology, Harvard University Press, Cambridge, MA, 1973.

Marmot, Michael. "Multi-Level Approaches to Understanding Social Determinants," in Lisa Berkman and Ichiro Kawachi (eds.), Social Epidemiology, Oxford University Press, Oxford, 1999.

Smith James P. "Healthy Bodies and Thick Wallets," Journal of Economic Perspectives. 13(2):145-66, 1999.

Smith, James P. "Why is Wealth Inequality Rising?" in Finis Welch (ed.), Increasing Income Inequality in America: The Facts, Causes, and Consequences, University of Chicago Press, 2000, pp. 83-116.

Smith, James P. "Unraveling the SES Health Connection,” manuscript, 2003.

Smith James P., and Raynard Kington. "Demographic and Economic Correlates of Health in Old Age,” Demography 34(1):159-170, February 1997.

Townsend, P., P. Phillimore, and A. Beattie. Health and Deprivation: Inequality and the North, Croom Helm, London, 1988.

Wadsworth, M.E.J., and D.J.L. Kuh. Childhood Influences on Adult Health: A Review of Recent Work from the British 1946 National Birth Cohort Study, the MRC National Survey of Health and Development, Pediatric and Perinatal Epidemiology, 11:2-20, 1997. 
Table 1

Pre-existing and New Health Conditions-Original HRS Cohort

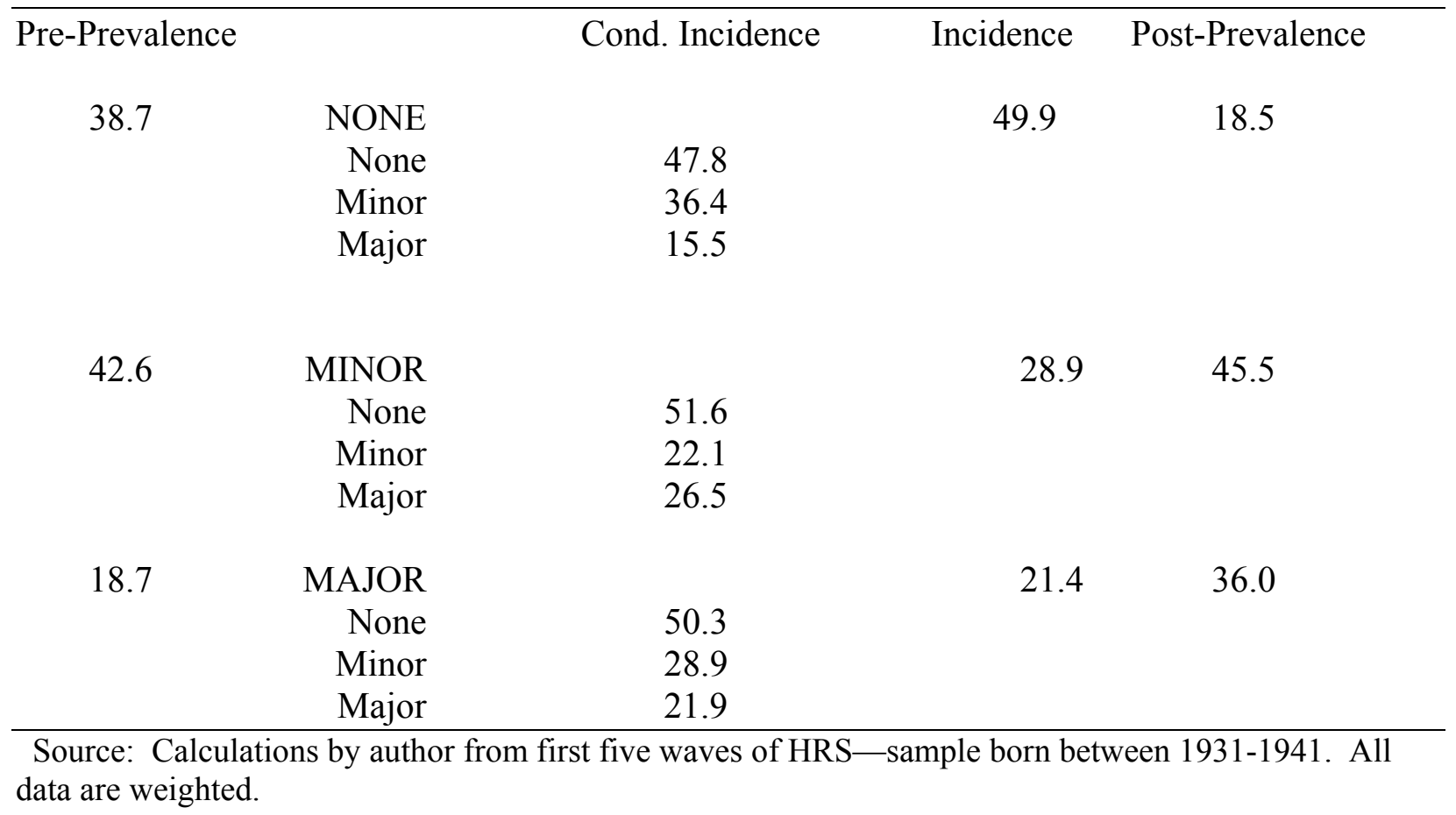


Table 2

Distribution of Out-of-Pocket Medical Expenditures Percentiles

\begin{tabular}{|c|c|c|c|c|c|c|c|c|}
\hline Percentiles & $10^{\text {th }}$ & $30^{\text {th }}$ & $50^{\text {th }}$ & $70^{\text {th }}$ & $90^{\text {th }}$ & $95^{\text {th }}$ & $98^{\text {th }}$ & Mean \\
\hline \multicolumn{9}{|c|}{ Wave 2 incidence of chronic condition } \\
\hline severe & 1,007 & 3,430 & 6,660 & 11,011 & 29,925 & 43,365 & 72,266 & 11,285 \\
\hline mild & 532 & 2,155 & 3,187 & 6,751 & 15,729 & 21,199 & 31,178 & 7,299 \\
\hline none all five waves & 414 & 1,579 & 3,164 & 5,668 & 12,463 & 18,356 & 30,904 & 5,776 \\
\hline \multicolumn{9}{|c|}{ Have health insurance at baseline } \\
\hline severe & 1,130 & 3,868 & 6,672 & 10,624 & 25,111 & 32,382 & 53,432 & 10,609 \\
\hline mild & 627 & 2,265 & 3,908 & 6,979 & 15,748 & 21,199 & 35,312 & 7,570 \\
\hline none all five waves & 496 & 1,633 & 3,235 & 5,688 & 12,170 & 17,584 & 30,811 & 5,738 \\
\hline \multicolumn{9}{|c|}{ Have no health insurance at baseline } \\
\hline severe. & 73 & 1,196 & 4,867 & 15,291 & 43,485 & 93,982 & 93,982 & 16,444 \\
\hline mild & 184 & 1,247 & 3,094 & 5,490 & 15,008 & 21,729 & 30,131 & 5,674 \\
\hline none all five waves & 153 & 1,138 & 2,787 & 5,773 & 14,958 & 20,692 & 39,489 & 6,168 \\
\hline
\end{tabular}

Calculations by author using HRS - between Waves 1-5. All data are weighted. 
Table 3

Impact of New Health Shock on Out-of-Pocket Medical Expenses

\begin{tabular}{|c|c|c|c|c|}
\hline \multicolumn{5}{|c|}{ Major Health Shock Between } \\
\hline Wave & W1-W2 & W2-W3 & W3-W4 & W4-W5 \\
\hline 2 & $1,720 *$ & & & \\
\hline 3 & $1,037 *$ & $2,052 *$ & & \\
\hline 4 & $893 *$ & $734^{*}$ & $1,490^{*}$ & \\
\hline 5 & $503 *$ & 401 & $607 *$ & $1,969 *$ \\
\hline Total & 4,153 & 3,187 & 2,097 & 1,969 \\
\hline \multicolumn{5}{|c|}{ Minor Health Shock Between } \\
\hline Wave & W1-W2 & W2-W3 & W3-W4 & W4-W5 \\
\hline 2 & 175 & & & \\
\hline 3 & 313 & $766^{*}$ & & \\
\hline 4 & 160 & 247 & $443^{*}$ & \\
\hline 5 & $567 *$ & $682 *$ & $625^{*}$ & $456^{*}$ \\
\hline Total & 1,215 & 1,695 & 1,065 & 456 \\
\hline
\end{tabular}

* Statistically significant at 5\%. 
Table 4

Fraction of Respondents Without Health Insurance

Major Health Onset by:

\begin{tabular}{cccccc} 
& $\begin{array}{c}\text { No Health } \\
\text { Onsets }\end{array}$ & Wave 1-2 & Wave 2-3 & Wave 3-4 & Wave 4-5 \\
\hline Wave 1 & 14.0 & 13.6 & 14.4 & 15.1 & 16.0 \\
Wave 2 & 12.4 & 8.0 & 14.2 & 12.1 & 15.6 \\
Wave 3 & 10.3 & 6.1 & 7.8 & 10.2 & 13.8 \\
Wave 4 & 9.4 & 6.6 & 7.6 & 6.0 & 9.2 \\
Wave 5 & 7.3 & 2.6 & 4.9 & 3.6 & 6.5 \\
\hline
\end{tabular}


Table 5

Changes in Type of Health Insurance

\begin{tabular}{|c|c|c|c|c|c|}
\hline No New Health Event & 1 & 2 & 3 & 4 & 5 \\
\hline No health insurance & 12.2 & 10.8 & 9.1 & 8.4 & 6.1 \\
\hline Employer only & 62.8 & 62.8 & 60.1 & 52.0 & 41.9 \\
\hline Government only & 5.2 & 7.5 & 13.0 & 19.4 & 25.9 \\
\hline Government and employer & 4.9 & 6.6 & 8.0 & 11.2 & 16.1 \\
\hline Personal only & 5.9 & 6.4 & 9.2 & 7.3 & 6.5 \\
\hline All other & 9.0 & 5.0 & 0.6 & 1.7 & 3.5 \\
\hline Severe Health Event, Wave 1 - 2 & 1 & 2 & 3 & 4 & 5 \\
\hline No health insurance & 11.9 & 6.3 & 5.1 & 4.9 & 1.6 \\
\hline Employer only & 58.6 & 57.8 & 44.8 & 34.4 & 23.7 \\
\hline Government only & 10.3 & 16.1 & 26.0 & 35.6 & 41.9 \\
\hline Government and employer & 5.1 & 9.1 & 16.8 & 20.7 & 23.7 \\
\hline Personal only & 4.5 & 3.9 & 7.4 & 4.0 & 1.6 \\
\hline All other & 9.6 & 6.8 & 0.1 & 0.4 & 7.5 \\
\hline Minor Health Event, Wave 1 - 2 & 1 & 2 & 3 & 4 & 5 \\
\hline No health insurance & 15.4 & 13.0 & 9.9 & 7.2 & 5.5 \\
\hline Employer only & 59.0 & 60.5 & 56.3 & 47.5 & 36.0 \\
\hline Government only & 6.0 & 9.7 & 17.6 & 23.6 & 29.1 \\
\hline Government and employer & 4.3 & 5.9 & 8.3 & 14.3 & 21.1 \\
\hline Personal only & 6.9 & 5.1 & 7.4 & 6.4 & 5.6 \\
\hline All other & 8.4 & 5.8 & 0.5 & 1.0 & 2.7 \\
\hline
\end{tabular}


Table 6

Probability of Working

\begin{tabular}{|c|c|c|c|c|}
\hline \multicolumn{5}{|c|}{ Major Health Shock } \\
\hline & W1-W2 & W2-W3 & W3-W4 & W4-W5 \\
\hline 2 & $-.148^{*}$ & & & \\
\hline 3 & -.054 & $-.156^{*}$ & & \\
\hline 4 & -.030 & -.024 & $-.091 *$ & \\
\hline 5 & -.036 & -045 & -049 & $-.112 *$ \\
\hline Total & -.268 & -.225 & -.140 & -.112 \\
\hline \multicolumn{5}{|c|}{ Minor Health Shock } \\
\hline & W1-W2 & W2-W3 & W3-W4 & W4-W5 \\
\hline 2 & $-.041 *$ & & & \\
\hline 3 & $-.036^{*}$ & -.031 & & \\
\hline 4 & -.017 & -.022 & -.019 & \\
\hline 5 & -.013 & -.004 & -.021 & -.015 \\
\hline Total & -.107 & -.057 & -.040 & -.015 \\
\hline
\end{tabular}


Table 7

Hours Worked Per Week

\begin{tabular}{|c|c|c|c|c|}
\hline \multicolumn{5}{|c|}{ Major Health Shock } \\
\hline & W1-W2 & W2-W3 & W3-W4 & W4-W5 \\
\hline 2 & $-4.02 *$ & & & \\
\hline 3 & 0.64 & $-4.31 *$ & & \\
\hline 4 & -0.60 & 0.63 & $-1.96^{*}$ & \\
\hline 5 & 0.17 & 0.16 & -0.68 & $-2.54 *$ \\
\hline Total & -3.83 & -3.50 & -2.64 & -2.54 \\
\hline \multicolumn{5}{|c|}{ Minor Health Shock } \\
\hline & W1-W2 & W2-W3 & W3-W4 & W4-W5 \\
\hline 2 & $-1.21 *$ & & & \\
\hline 3 & -0.99 & $-1.51 *$ & & \\
\hline 4 & 0.40 & -0.17 & $-1.54 *$ & \\
\hline 5 & 0.30 & 0.12 & 0.15 & 0.07 \\
\hline Total & -1.49 & -1.56 & -1.39 & 0.07 \\
\hline
\end{tabular}


Table 8

Impact of Health Shock on Household Income

\section{Major Health Shock}

\begin{tabular}{|c|c|c|c|c|}
\hline & W1-W2 & W2-W3 & W3-W4 & W4-W5 \\
\hline 2 & $-4,033 *$ & & & \\
\hline 3 & $-1,258$ & -737 & & \\
\hline 4 & -698 & $-3,231$ & $-2,239$ & \\
\hline 5 & -269 & -460 & -139 & $-3,601 *$ \\
\hline $\begin{array}{l}\text { Total Yearly } \\
\text { Income Loss }\end{array}$ & $-6,258$ & $-4,428$ & $-2,478$ & $-3,601$ \\
\hline $\begin{array}{l}\text { Cumulative } \\
\text { Income Loss }\end{array}$ & $-36,884$ & $-13,828$ & $-6,856$ & $-3,601$ \\
\hline \multicolumn{5}{|c|}{ Minor Health Shock } \\
\hline & W1-W2 & W2-W3 & W3-W4 & W4-W5 \\
\hline 2 & -498 & & & \\
\hline 3 & -988 & 20 & & \\
\hline 4 & -44 & $-3,012 *$ & $-1,423$ & \\
\hline 5 & -169 & 125 & $-2,680 *$ & 351 \\
\hline $\begin{array}{l}\text { Total Yearly } \\
\text { Income Loss }\end{array}$ & $-1,699$ & $-2,967$ & $-4,103$ & 351 \\
\hline $\begin{array}{l}\text { Cumulative } \\
\text { Income Loss }\end{array}$ & $-8,727$ & $-8,811$ & $-6,949$ & 351 \\
\hline
\end{tabular}


Table 9

Cumulative Effects of New Health Events

$\begin{array}{llll}\text { W1-W2 } & \text { W2-W3 } & \text { W3-W4 } & \text { W4-W5 }\end{array}$

\section{HRS - sample}

Major Health Event

Cumulative

Income Loss

$-36,884$

$-13,828$

$-6,856$

$-3,601$

Cumulative

Income Loss +

Increase Expenses

$-48,941$

$-19,338$

$-9,805$

$-5,901$

\section{AHEAD - sample}

Cumulative

Income Loss +

Increase Expenses

$-11,346$

$-3,553$

$-3,005$

\section{HRS - sample}

Minor Health Event

Cumulative

Income Loss

$-8,727$

$-8,811$

$-6,949$

351

Cumulative

Income Loss +

Increase Expenses

$-11,544$

$-11,584$

$-8,610$

$-316$

\section{AHEAD - sample}

Cumulative

Income Loss +

Increase Expenses

5,926

$-6,838$

$-702$

Note: AHEAD sample waves moved over one column. 
Table 10

Cumulative Income Loss and Cumulative OOP Medical Expenses

\begin{tabular}{|c|c|c|c|c|c|c|c|c|}
\hline & \multicolumn{4}{|c|}{$\begin{array}{c}\text { Cumulative Income Loss and OOP } \\
\text { Medical Expenses }\end{array}$} & \multicolumn{4}{|c|}{ Wealth5 - Wealth1 } \\
\hline & Estimate & "t $\mathrm{t} "$ & Estimate & " $t$ " & Estimate & "t" & Estimate & "t" \\
\hline Intercept & 30,503 & 0.41 & 21,124 & 0.28 & 91,091 & 0.48 & 44,937 & 0.24 \\
\hline Cohort 1935-37 & $-34,376$ & -2.83 & $-29,081$ & -2.33 & 51,748 & 1.67 & 59,433 & 1.90 \\
\hline Cohort 1938 Plus & $-91,859$ & -8.55 & $-77,832$ & -7.07 & 36,613 & 1.34 & 56,007 & 2.04 \\
\hline Health Excellent & $-23,402$ & -1.30 & $-3,574$ & -0.19 & $-10,053$ & -0.22 & $-10,193$ & -0.22 \\
\hline Health Very Good & $-18,217$ & -1.12 & $-8,747$ & -0.52 & 41,862 & 1.01 & 39,372 & 0.94 \\
\hline Health Good & $-1,984$ & 0.13 & 5,786 & 0.37 & 32,719 & 0.85 & 39,605 & 1.02 \\
\hline Functional & & & & & & & & \\
\hline Limitations Scale & 476 & 1.14 & 378 & 0.88 & 86 & 0.08 & 215 & 0.20 \\
\hline Female & 29,223 & 2.93 & 29,905 & 2.92 & $-18,124$ & -0.72 & $-17,917$ & -0.68 \\
\hline Black & 9,920 & 0.72 & 12,035 & 0.85 & $-83,932$ & -2.42 & $-62,914$ & -1.80 \\
\hline Hispanic & 20,222 & 1.13 & 12,540 & 0.68 & $-79,374$ & -1.75 & $-59,523$ & -1.31 \\
\hline Income & 2.445 & 20.6 & & & 1.853 & 6.17 & 0.3064 & 1.14 \\
\hline Wealth & -0.2800 & 37.6 & -0.2096 & 30.8 & -0.2152 & 11.21 & & \\
\hline Ed 12-15 & $-5,519$ & -0.48 & 15,422 & 1.31 & 16,398 & 0.56 & 15,596 & 0.53 \\
\hline Ed College or more & $-124,676$ & -8.20 & $-58,968$ & -3.86 & 134,326 & 3.47 & 122,282 & 3.14 \\
\hline Minor Onset wave 2 & 13,247 & 0.94 & 11,128 & 0.77 & $-13,364$ & -0.37 & $-13,074$ & -0.36 \\
\hline Major Onset wave 2 & 47,007 & 2.33 & 52,158 & 2.52 & $-78,266$ & -1.52 & $-78,130$ & -1.51 \\
\hline $\mathrm{R}$ squared & .19 & & .14 & & .026 & & .012 & \\
\hline
\end{tabular}


Table 11

Probits for Future Onset of Chronic Condition

\begin{tabular}{|c|c|c|c|c|}
\hline & \multicolumn{2}{|c|}{ Major } & \multicolumn{2}{|c|}{ Minor } \\
\hline & Estimate & Chi Square & Estimate & Chi Square \\
\hline Intercept & -0.8489 & 10.14 & -1.9624 & 37.91 \\
\hline Cohort 1935-37 & -0.1920 & 19.78 & -0.0799 & 4.02 \\
\hline Cohort 1938 Plus & -0.1888 & 24.99 & -0.1535 & 19.35 \\
\hline Health Excellent & -0.2314 & 13.57 & -0.2396 & 16.76 \\
\hline Health Very Good & -0.1766 & 9.95 & -0.0951 & 3.17 \\
\hline Health Good & -0.0770 & 2.27 & 0.0302 & 0.37 \\
\hline Functional Limitations Scale & 0.0041 & 8.63 & 0.0058 & 18.15 \\
\hline BMI & 0.0172 & 1.47 & 0.1113 & 33.25 \\
\hline BMI squared & -0.0002 & 0.85 & -0.0012 & 14.29 \\
\hline Vigorous exercise & -0.0786 & 3.94 & -0.0266 & 0.57 \\
\hline Smoker & 0.1523 & 6.68 & 0.0275 & 0.25 \\
\hline Number of cigs & 0.0075 & 10.69 & 0.0005 & 0.06 \\
\hline More than 3 drinks & -0.1583 & 4.55 & -0.0339 & 0.24 \\
\hline Female & -0.1918 & 30.12 & 0.0360 & 1.25 \\
\hline Black & -0.1245 & 6.70 & 0.1396 & 10.04 \\
\hline Hispanic & -0.2994 & 20.40 & 0.0600 & 1.09 \\
\hline Income & 0.0111 & 0.06 & -0.0063 & 0.03 \\
\hline Wealth & -0.0046 & 2.26 & -0.0005 & 0.05 \\
\hline Change in stock wealth & -0.0004 & 0.44 & 0.0004 & 0.88 \\
\hline Ed 12-15 & -0.1108 & 7.78 & -0.0912 & 5.96 \\
\hline Ed College or more & -0.0844 & 2.43 & -0.1588 & 10.26 \\
\hline
\end{tabular}

Models also control for presence of baseline chronic condition, region of residence, health insurance, and missing value indicators. Income and wealth measured in $\$ 100,000$ of dollars and the change in stock wealth in $\$ 10,000$ of dollars. 
Table 12

Probits for Future Onset of Chronic Condition

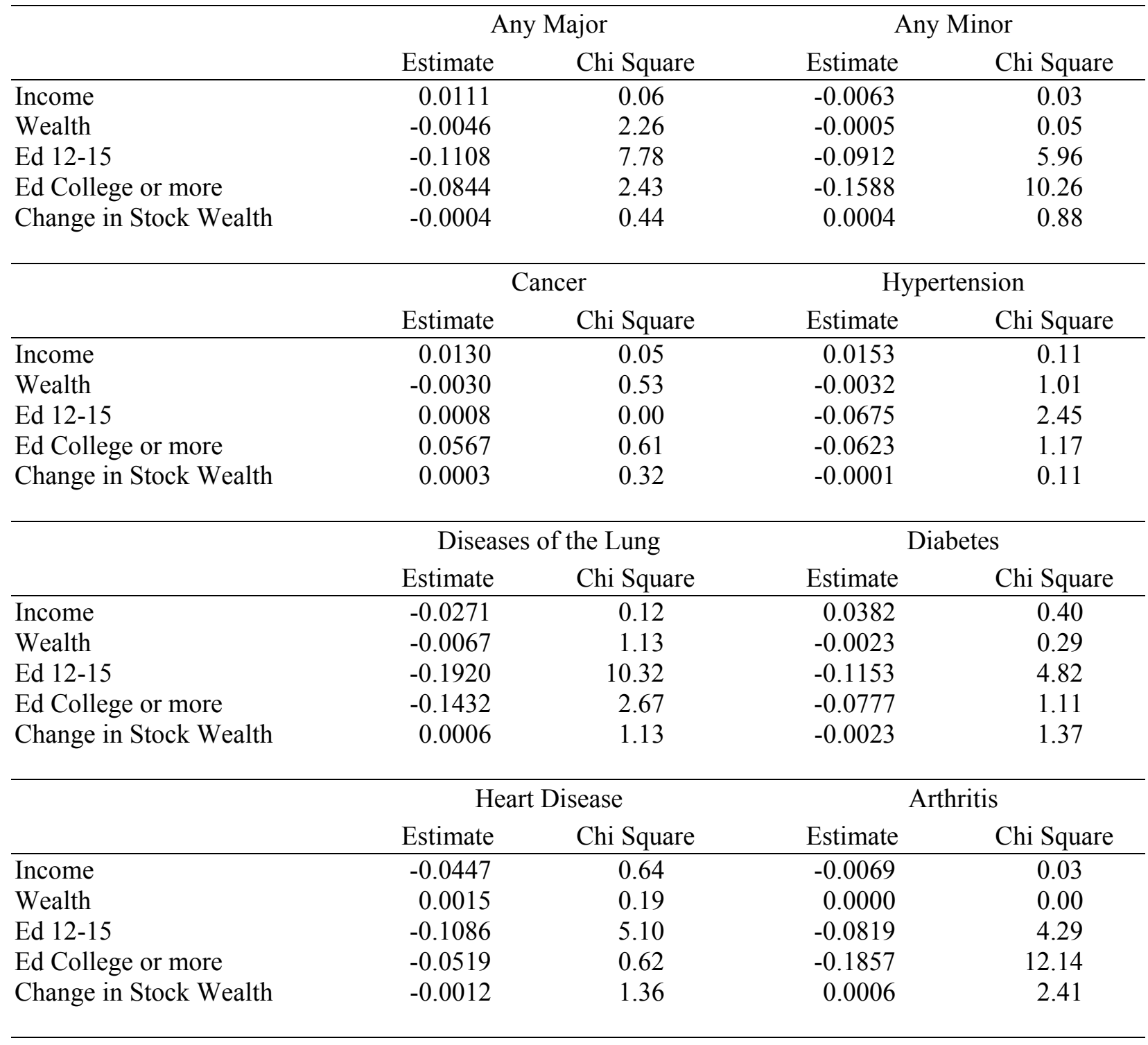

Stroke

\begin{tabular}{lrc} 
& Estimate & Chi Square \\
\hline Income & 0.0683 & 0.70 \\
Wealth & -0.0175 & 3.83 \\
Ed 12-15 & -0.0390 & 0.36 \\
Ed College or more & -0.0746 & 0.59 \\
Change in Stock Wealth & -0.0017 & 0.57 \\
\hline
\end{tabular}

Models also control for other variables-see footnote to Table 11. Income and wealth measured in $\$ 100,000$ of dollars and the change in stock wealth in $\$ 10,000$ of dollars. 
Table 13

Probits for Future Onset of Major Chronic Condition

\begin{tabular}{|c|c|c|c|c|}
\hline & \multicolumn{2}{|c|}{ Major } & \multicolumn{2}{|c|}{ Major Extended } \\
\hline & Estimate & Chi Square & Estimate & Chi Square \\
\hline Intercept & -0.8649 & 10.14 & -0.8963 & 7.12 \\
\hline Cohort 1935-37 & -0.1920 & 19.78 & -0.1778 & 14.00 \\
\hline Cohort 1938 Plus & -0.1888 & 24.99 & -0.1617 & 13.66 \\
\hline Health Excellent & -0.2314 & 13.57 & -0.2058 & 8.64 \\
\hline Health Very Good & -0.1766 & 9.95 & -0.1629 & 6.79 \\
\hline Health Good & -0.0770 & 2.27 & -0.0624 & 1.18 \\
\hline Functional Limitations Scale & 0.0041 & 8.63 & 0.0037 & 5.31 \\
\hline BMI & 0.0172 & 1.47 & 0.0199 & 1.66 \\
\hline BMI squared & -0.0002 & 0.85 & -0.0002 & 1.01 \\
\hline Vigorous exercise & -0.0786 & 3.94 & -0.0917 & 4.60 \\
\hline Smoker & 0.1523 & 6.68 & 0.0997 & 2.10 \\
\hline Number of cigs & 0.0075 & 10.69 & 0.0103 & 15.69 \\
\hline More than 3 drinks & -0.1583 & 4.55 & -0.1669 & 4.22 \\
\hline Female & -0.1918 & 30.12 & -0.1893 & 20.96 \\
\hline Black & -0.1245 & 6.70 & -0.0556 & 0.97 \\
\hline Hispanic & -0.2994 & 20.40 & -0.2098 & 7.34 \\
\hline Income & 0.0111 & 0.06 & 0.0456 & 0.93 \\
\hline Wealth & -0.0046 & 2.26 & -0.0040 & 1.60 \\
\hline Change in stock wealth & -0.0004 & 0.44 & -0.0008 & 1.06 \\
\hline Ed 12-15 & -0.1108 & 7.78 & -0.0783 & 2.66 \\
\hline Ed College or more & -0.0844 & 2.43 & -0.0483 & 0.52 \\
\hline Ex smoker & & & 0.0195 & 0.20 \\
\hline Expose to hazard on job & & & 0.0200 & 0.21 \\
\hline \# of years exposed & & & 0.0021 & 0.99 \\
\hline Memory test & & & 0.0118 & 2.53 \\
\hline WAIS scale & & & -0.0001 & 0.00 \\
\hline Health Ex or VG as child & & & -0.0870 & 4.68 \\
\hline Not poor during childhood & & & -0.0949 & 6.31 \\
\hline Mother's ed & & & 0.0028 & 0.18 \\
\hline Father's ed & & & -0.0018 & 0.09 \\
\hline Father alive & & & -0.1362 & 1.34 \\
\hline Age of father's death & & & 0.0002 & 0.01 \\
\hline Mother alive & & & -0.0743 & 0.49 \\
\hline Age of Mother's death & & & -.00002 & 0.01 \\
\hline
\end{tabular}


Table 14

Probits for Future Onset of Minor Chronic Condition

\begin{tabular}{|c|c|c|c|c|}
\hline & \multicolumn{2}{|c|}{ Minor } & \multicolumn{2}{|c|}{ Minor Extended } \\
\hline & Estimate & Chi Square & Estimate & Chi Square \\
\hline Intercept & -1.9624 & 38.19 & -1.7780 & 21.54 \\
\hline Cohort 1935-37 & -0.0799 & 4.06 & -0.1122 & 6.58 \\
\hline Cohort 1938 Plus & -0.1535 & 19.29 & -0.1761 & 19.12 \\
\hline Health Excellent & -0.2396 & 16.65 & -0.2488 & 14.57 \\
\hline Health Very Good & -0.0951 & 2.96 & -0.0805 & 1.83 \\
\hline Health Good & 0.0302 & 0.37 & 0.0224 & 0.16 \\
\hline Functional Limitations Scale & 0.0058 & 18.39 & 0.0060 & 15.50 \\
\hline BMI & 0.1113 & 32.97 & 0.1187 & 31.13 \\
\hline BMI squared & -0.0012 & 13.99 & -0.0013 & 13.40 \\
\hline Vigorous exercise & -0.0266 & 0.42 & -0.0231 & 0.38 \\
\hline Smoker & 0.0275 & 0.24 & 0.0495 & 0.60 \\
\hline Number of cigs & 0.0005 & 0.07 & 0.0014 & 0.30 \\
\hline More than 3 drinks & -0.0339 & 0.30 & -0.0271 & 0.13 \\
\hline Female & 0.0360 & 1.24 & 0.0704 & 3.49 \\
\hline Black & 0.1396 & 9.96 & 0.1366 & 7.00 \\
\hline Hispanic & 0.0600 & 1.22 & 0.0614 & 0.83 \\
\hline Income & -0.0063 & 0.02 & -0.0044 & 0.01 \\
\hline Wealth & -0.0005 & 0.00 & -0.0001 & 0.00 \\
\hline Change in stock wealth & 0.0004 & 0.88 & 0.0003 & 0.75 \\
\hline Ed 12-15 & -0.0912 & 6.02 & -0.0527 & 1.38 \\
\hline Ed College or more & -0.1588 & 10.46 & -0.0927 & 2.33 \\
\hline Ex smoker & & & 0.0536 & 2.12 \\
\hline Expose to hazard on job & & & -0.0261 & 0.44 \\
\hline \# of years exposed & & & 0.0007 & 0.12 \\
\hline Memory test & & & -0.0055 & 0.68 \\
\hline WAIS scale & & & -0.0035 & 0.28 \\
\hline Health Ex or VG as child & & & 0.0042 & 0.01 \\
\hline Not poor during childhood & & & 0.0155 & 0.20 \\
\hline Mother's ed & & & 0.0004 & 0.00 \\
\hline Father's ed & & & -0.0046 & 0.72 \\
\hline Father alive & & & -0.2001 & 3.32 \\
\hline Age of father's death & & & -0.0014 & 0.88 \\
\hline Mother alive & & & -0.2465 & 6.51 \\
\hline Age of Mother's death & & & -.00028 & 4.60 \\
\hline
\end{tabular}


Appendix Table A

Types of Government Insurance

\begin{tabular}{lrrrrr}
\hline No New Health Event & 1 & 2 & 3 & 4 & 5 \\
\hline Medicare & 37.8 & 44.5 & 59.5 & 75.6 & 81.4 \\
Medicaid & 15.7 & 13.2 & 12.0 & 6.1 & 4.2 \\
Champus & 37.7 & 30.5 & 19.5 & 10.5 & 5.8 \\
Medicare and Medicaid & 3.3 & 4.1 & 6.9 & 5.9 & 5.7 \\
All other & 5.5 & 7.7 & 2.1 & 2.1 & 2.9 \\
\hline
\end{tabular}

\begin{tabular}{lrrrrr}
\hline Severe Health Event, Wave 1 - 2 & 1 & 2 & 3 & 4 & 5 \\
\hline Medicare & 40.8 & 50.7 & 62.7 & 73.8 & 74.4 \\
Medicaid & 21.8 & 22.3 & 16.4 & 8.1 & 4.8 \\
Champus & 26.2 & 15.1 & 6.5 & 4.7 & 4.1 \\
Medicare and Medicaid & 2.4 & 7.4 & 13.1 & 11.1 & 15.6 \\
All other & 8.8 & 4.6 & 1.3 & 2.4 & 0.9 \\
\hline
\end{tabular}

\begin{tabular}{lrrrrr}
\hline Minor Health Event, Wave 1 - 2 & 1 & 2 & 3 & 4 & 5 \\
\hline Medicare & 37.3 & 51.9 & 62.2 & 75.1 & 79.0 \\
Medicaid & 19.7 & 14.8 & 16.0 & 6.0 & 4.7 \\
Champus & 28.0 & 21.4 & 10.7 & 7.3 & 5.5 \\
Medicare and Medicaid & 3.8 & 4.4 & 9.3 & 10.1 & 9.8 \\
All other & 11.0 & 7.5 & 1.9 & 1.5 & 1.1 \\
& & & & & \\
\hline
\end{tabular}

